\title{
Personalized e-Learning Implementation - The GIS Case
}

\author{
Athanasios D. Styliadis, Ioannis D. Karamitsos, Dimitrios I. Zachariou
}

\begin{abstract}
Personalized e-learning implementation is recognized as among one of the most interesting research areas in the distance learning Web-based education. In particular, the GIS e-learning initiatives that incorporate — by default - a number of sequencing spatial techniques (i.e. spatial objects selection and sequencing), will well benefit from a welldefined personalized e-learning implementation with embedded spatial functionality. This is the case addressed in this paper.

The GIS e-learning implementation introduced in the current paper is based on a set of teaching (lecturing) rules according to the cognitive style of learning preferences of both the learners and the lecturers as well. It is important to note that, in spite of the fact that most of these teaching rules are generic (i.e. domain, view and user independent), there are no so far well-defined and commonly accepted rules on how the learning spatial GIS objects and techniques should be selected and how they should be sequenced to make "instructional sense" in a Web-based GIS course.
\end{abstract}

Keywords: e-Learning, Distance Learning, GIS, LIS, AM/FM, Spatial Sciences.

\section{Introduction}

GIS learning object selection is the first step to adaptive space navigation and adaptive course sequencing with GIS (space) functionality. Adaptive navigation seeks to present the GIS learning objects associated with an on-line course in an optimized order, where the optimisation criteria takes into consideration the learner's background and performance in related learning objects [2], whereas adaptive course sequencing is defined as the process that selects learning objects from a digital repository and sequence them in a way which is appropriate for the targeted GIS learning community or individuals $[16,11,17]$. Selection and sequencing is recognized as among the most interesting research questions in intelligent web-based GIS education [13,6].

Although many types of intelligent learning systems with no GIS functionality are available, in the proposed GIS case five key components could be identified, which are common in most GIS systems, namely: data acquisition, retrieval and analysis, preliminary data processing, database construction, and communication and visualization. Figure 1 provides a view of the interactions between these five GIS modules [18].

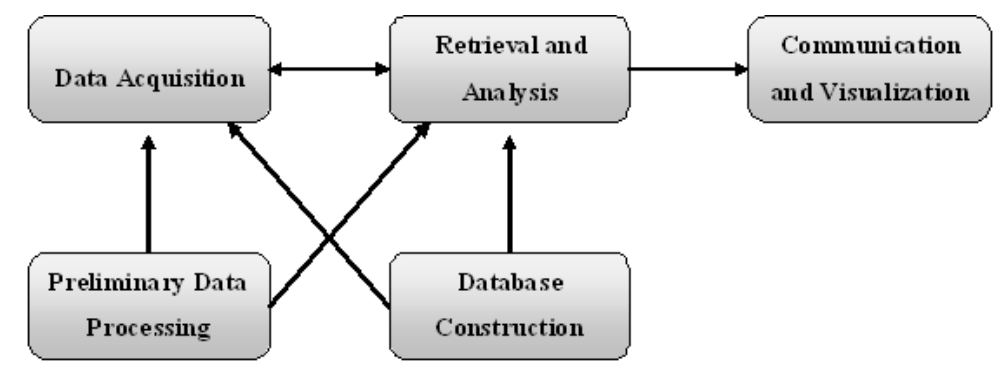

Figure 1: The Main Components of a GIS Intelligent Learning Systems

In most intelligent learning systems that incorporate course sequencing techniques, the pedagogical module is responsible for setting the principles of content selection and instructional planning. The selection of content (in our case, the GIS learning objects) is based on a set of teaching rules according to the topology-based cognitive style or learning preferences of the learners $[3,15]$. In spite of the fact that most of these rules are generic (i.e. domain independent), there are no well defined and commonly accepted rules on how the GIS learning objects should be selected and how they should be sequenced to make "instructional sense" with GIS functionality [14]. Moreover, in order to design highly adaptive learning systems a huge set of topology-based rules is required, since dependencies between educational characteristics of GIS learning objects and learners are rather complex [8, 12, $9,10]$. 
In this paper, the learning object selection problem in GIS intelligent learning systems is addressed by proposing a methodology that instead of "forcing" an instructional designer to manually define the set of selection rules; produces a decision model that mimics the way the designer decides, based on the observation of the designer's reaction over a small-scale learning object selection problem.

In the next (second) section the GIS learning object selection process is discussed as a part of a spatial-course sequencing. The third section discusses a topology-based filtering process of GIS learning objects used for reduction of learning objects searching space and proposes GIS metadata elements that can be used for learning object filtering according to the Open GIS Consortium guidelines (standards) for GIS functionality.

\section{GIS Learning Object Selection in Spatial-Course Sequencing}

In automatic and semi-automatic course sequencing, the main idea is to generate a course suited to the needs of the learners. As described in the literature, two main approaches for automatic and semi-automatic course sequencing have been identified: Adaptive Courseware Generation (ACG) and Dynamic Courseware Generation (DCG) [3].

In ACG the goal is to generate an individualized course taking into account specific learning goals, as well as, the initial level of the student's knowledge. The entire course is adaptively generated before presenting it to the learner, instead of generating a course incrementally, as in a traditional sequencing context. In DCG on the other hand, the system observes the student progress during his interaction with the course and dynamically adapts the course according to the specific student needs and requirements. If the student's performance does not meet the expectations, the course is dynamically re-planned. The benefit of this approach is that it applies as much adaptivity to an individual student as possible.

Both, the above mentioned techniques, in the case of GIS lecturing employ a pre-filtering topology-based mechanism to generate a group ("pool") of GIS learning objects that match the general content requirements. This pool can be generated from both distributed and local GIS learning object repositories, provided that the appropriate access controls have been granted. The filtering process is based on general requirements such as topology, GIS functionality, characteristics of the teaching language, the media of the targeted GIS learning objects, as well as, the use of ontologies and topology for the domain in question (known as the Spatial Knowledge module). The result of the filtering process falls in a virtual pool of GIS learning objects that will act as an input space for the content selector (GIS functionality).

After the creation of the initial pool of the GIS learning objects, the content selection process and the underlined topology is applied based on learner characteristics, such as accessibility and competency characteristics or even historical information about related learning activities, included in the Student Model module. In the next section some filtering elements based on the Open GIS Consortium (O-GIS . C) Learning Object Metadata (LOM) standard are presented and the methodology is analyzed for the proposed content selection phase of a semi-automatic GIS course sequencing with spatial functionality.

\section{GIS Learning Object Filtering}

Generally, the main goal of a filtering process is the reduction of the searching space. GIS Learning Object Repositories (G.LOR) often contain hundreds of thousands of GIS learning objects, thus the selection process may require a significant computational time and effort. In most intelligent learning systems, learning object filtering is based, either on the knowledge domain they cover, or on the media type characteristics they contain [11].

In the Open GIS Consortium's (O-GIS . C) spatial metadata model, there exist a number of elements covering requirements such as GIS functionality, topology, geometry, subject, teaching language, media type of the targeted GIS learning object, etc. Figure 2 presents the O-GIS . C elements identified for each one of the above mentioned topology-based filtering categories and the conditions required.

Alternatively, filtering can be based on integration of the O-GIS . C metadata model elements and ontologies $[19,16]$. Those approaches assume that both the domain model and the learning objects themselves use the same ontology [14] and limit the filtering only to knowledge domain filtering with GIS functionality. 


\begin{tabular}{|c|c|c|c|}
\hline Filters & O-GIS.C Function & Explanation & Usage \\
\hline \multirow{3}{*}{$\begin{array}{l}\text { Surveying } \\
\text { \& } \\
\text { Monitorin } \\
\text { g }\end{array}$} & $\begin{array}{l}\text { Topographic and Land } \\
\text { Survey }\end{array}$ & $\begin{array}{l}\text { A keyword or phrase describing the } \\
\text { topic of a GIS Learning Object }\end{array}$ & $\begin{array}{c}\text { O-GIS.C/Classification/ } \\
\text { Purpose }=\text { "Geometry, } \\
\text { Topology" }\end{array}$ \\
\hline & $\begin{array}{l}\text { Hydrology, Marine Survey } \\
\text { and Geodesy }\end{array}$ & $\begin{array}{l}\text { The time and geography or region } \\
\text { to which a GIS Learning Object applies. }\end{array}$ & $\begin{array}{c}\text { O-GIS.C/Classification/ } \\
\text { Purpose = "Sea Level, Datum" }\end{array}$ \\
\hline & Soil \& Geological Surveys & $\begin{array}{c}\text { This category describes where a } \\
\text { Learning Object falls within a particular } \\
\text { Classification system. }\end{array}$ & $\begin{array}{l}\text { O-GIS.C/Classification/ } \\
\text { Purpose = "Land, Material" }\end{array}$ \\
\hline \multirow{2}{*}{ Navigation } & City Modelling \& Biosphere & $\begin{array}{l}\text { The primary human language/s used } \\
\text { within a Learning Object. }\end{array}$ & $\begin{array}{l}\text { O-GIS.C/Classification/ } \\
\text { Purpose = "3-D Model" }\end{array}$ \\
\hline & $\begin{array}{l}\text { Archaeology \& Historical } \\
\text { Sites }\end{array}$ & $\begin{array}{c}\text { The human language and culture used by the } \\
\text { typical intended user of a GIS Learning } \\
\text { Object }\end{array}$ & $\begin{array}{c}\text { O-GIS.C/Classification/ } \\
\text { Purpose = "History, Culture" }\end{array}$ \\
\hline \multirow{5}{*}{$\begin{array}{l}\text { Networks } \\
\text { \& Utilities } \\
\text { Maintenan } \\
\text { ce } \\
\text { (AM/FM) }\end{array}$} & Asset Management & $\begin{array}{l}\text { Technical data type/s of all the } \\
\text { components of a GIS Learning Object }\end{array}$ & $\begin{array}{c}\text { O-GIS.C/Classification/ } \\
\text { Purpose = "Profit, Money" }\end{array}$ \\
\hline & Marketing Market & The Marketing GIS Learn & $\begin{array}{l}\text { O-GIS.C/Classification/ } \\
\text { Purpose = "Profit, Sale" }\end{array}$ \\
\hline & Oil \& Gas Network & AM/FM Learning Objects & $\begin{array}{l}\text { O-GIS.C/Classification/ } \\
\text { Purpose = "Automated } \\
\text { Mapping (AM)" }\end{array}$ \\
\hline & Water Supply Network & $\begin{array}{l}\text { The completion status or condition of a } \\
\text { AM/FM GIS Learning Object }\end{array}$ & $\begin{array}{l}\text { O-GIS.C/Lifecycle/Status ! = } \\
\text { "Water" }\end{array}$ \\
\hline & Electricity Network & $\begin{array}{l}\text { Whether use of a GIS Learning Object } \\
\text { requires some kind of power. }\end{array}$ & $\begin{array}{l}\text { O-GIS.C/Classification/ } \\
\text { Purpose = "Facilities } \\
\text { Management (FM)" }\end{array}$ \\
\hline
\end{tabular}

Figure 2: Elements for GIS Learning Object Filtering

\section{The GIS Learning Object Selection Procedure}

Typically, the design of highly adaptive learning systems requires a huge set of rules, since dependencies between educational characteristics of learning objects and learners are rather complex. This complexity introduces several problems on the definition of the rules required [20,4], namely:

Inconsistency, when two or more rules are conf1icting.

Conf1uence, when two or more rules are equivalent.

Insufficiency, when one or more rules required have not been defined.

The proposed methodology is based on an intelligent mechanism that tries to mimic an instructional designer's decision model on the selection of the GIS learning objects. For this purpose, a framework that attempts to construct a suitability function that maps GIS learning object characteristics over learner characteristics and vice versa is designed.

The main advantage of this method is that it requires less effort by the instructional designer, since instead of identifying a huge set of rules related to space and topology, only the designer's selection from a small set of GIS learning objects over a reference set of learners is needed. The machine learning technique will try then to discover the dependence between GIS learning object and learner characteristics that produce the same selection of GIS learning objects per learner as the instructional designer did [1, 13, 20].

The proposed methodology does not depend on the characteristics used for learning objects and learner modelling, thus can be used for extraction of even complex pedagogy-related dependencies. It is obvious that since characteristics/requirements like the domain are used for filtering, the dependencies produced are quite generic, depending only on the educational characteristics of the content and the cognitive characteristics of the learner GIS student $[5,2,16]$.

Figure 2 presents a graphical representation of the proposed selection model extraction framework, which it is consisting of the following three main steps:

\section{1) The 3-D Modelling and Selection of GIS Criteria}

The selection methodology is generic, independent of the learning object and the learner characteristics used for the selection. In the proposed method experiment, GIS learning object characteristics was used derived from 


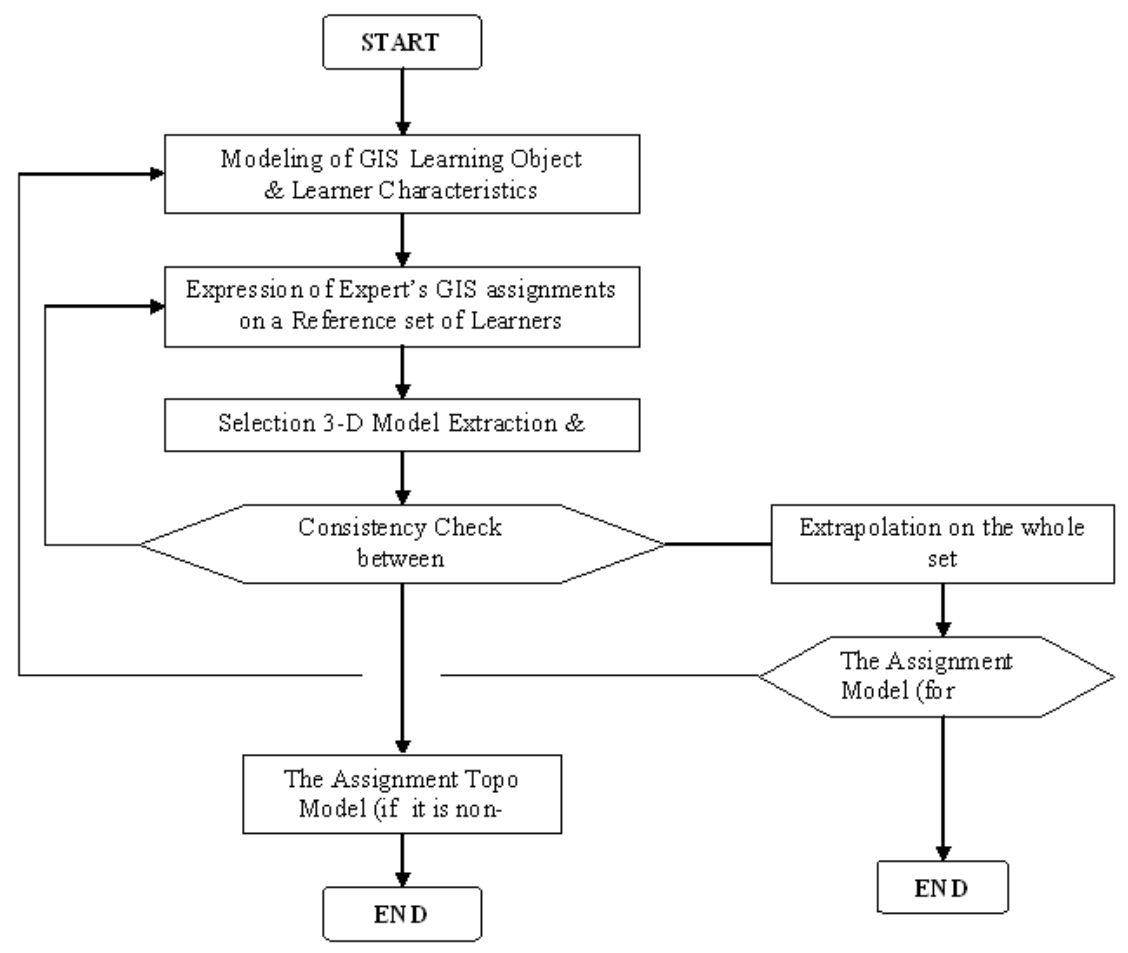

Figure 3: Selection Model Extraction Framework

the O-GIS . C standard, and learner characteristics derived from the IMS Global Learning Consortium Inc. Learner Information Package (LIP) specification.

There exist many criteria affecting the decision of GIS learning objects selection. Those criteria that lead to a straightforward exclusion of learning objects, such as the topology, the subject, the language and the media type and the GIS functionality are used for filtering. The rest set of criteria such as the educational characteristics of GIS learning objects are used for selection model extraction, since the dependencies of those criteria can model the pedagogy applied by the instructional designer, when selecting learning objects.

Those criteria, due to the complexity of interdependencies between them, are the ones that cannot be directly mapped to rules from the instructional designer. Thus an automatic or semi-automatic extraction method, like the proposed one, is needed.

\section{2) The Selection Model Extraction}

After identifying the set of the characteristics and the criteria (see: step 1) that will be used as the input space of the I/O selector, the extract procedure for each GIS learning object characteristic and the expert's suitability evaluation model over a reference set of LIP-based characterized learners is presented.

The input to this phase is the O-GIS.C characteristics of a reference set of learning objects, the IMS LIP characteristics of a reference set of learners and the suitability preference of an expert for each of the GIS learning objects over the whole reference set of learners.

The model extraction methodology has the following formulation:

Let us consider a set of learning objects, called $A$, which is valued by a set of criteria $g=\left(g_{1}, \ldots, g_{n}\right)$. The assessment model of the suitability of each GIS learning object for a specific learner, leads to the aggregation of all criteria into a unique criterion that we call a suitability function $S(g)=S\left(g_{1}, \ldots, g_{n}\right)$. 
We define the suitability function as an additive function of the form

$$
S(g)=\sum_{i=1}^{n} S_{i}\left(g_{i}\right)
$$

with the following additional notation:

- $S_{i}\left(g_{i}\right)$ : Marginal suitability of the $i$ th selection criterion valued $g_{i}$,

- $S(g)$ : Global suitability of a learning object.

The marginal suitability evaluation for the criterion gi is calculated using the formula

$$
S_{i}(x)=a_{i}+b_{i} x \exp \left(-c_{i} x^{2}\right)
$$

where $x$ is the corresponding value of the gi GIS learning object selection criterion. This formula produces, according to parameters $a, b$ and $c$ as well as the value space of each criterion, the main criteria forms, we have identified:

- Monotonic form: when the marginal suitability of a criterion is a monotonic function.

- Non monotonic form: when the marginal suitability of a criterion is a non-monotonic function.

The calculation of the optimal values of parameters $a, b$ and $c$ for each selection criterion is the subject of the Knowledge Model Extraction step.

Let us call $N$ the strict preference relation and $E$ the indifference relation. If $S_{O_{1}}$ is the global suitability of a learning object $O_{1}$ and $S_{O_{2}}$ is the global suitability of a learning object $O_{2}$, then the following properties generally hold for the suitability function $S$ :

$$
S_{O_{1}}>S_{O_{2}} \Longleftrightarrow\left(O_{1}\right) P\left(O_{2}\right)
$$

and the relation $R=P \cup I$ is a week order relation

$$
S_{O_{1}}=S_{O_{2}} \Longleftrightarrow\left(O_{1}\right) I\left(O_{2}\right)
$$

The expert's requested information then consists of the weak order $R$ defined on $A$ for several learner instances. Using the provided weak order relation $R$ and based on the form definition of each learning object characteristic we can define the suitability differences $\Delta=\left(\Delta_{1}, \ldots, \Delta_{m-1}\right)$, where $m$ is the number of learning objects in the reference set $A$ and $\Delta_{k}=S_{O_{k}}-S_{O_{k+1}} \geq 0$, depending on the suitability relation of $(k)$ and $(k+1)$ preferred learning object for a specific learner of the reference set.

We can introduce an error function e for each suitability difference:

$$
\Delta_{k}=S_{O_{k}}-S_{O_{k+1}}+e_{k} \geq 0
$$

Using constrained optimization techniques, we can then solve the non-linear problem:

$$
\operatorname{Minimize} \sum_{j=1}^{m-1}\left(e_{j}\right)^{2}
$$

subject to the constraints:

$$
\left.\begin{array}{lll}
\Delta_{j}>0 & \text { if } & O_{j} P O_{j+1} \\
\Delta_{j}=0 & \text { if } & O_{j} I O_{j+1}
\end{array}\right\}
$$

for each one of the learners of the reference set.

This optimisation problem will lead to the calculation of the optimal values of the parameter $a, b$ and $c$ for each GIS learning object selection criteria over the reference set of learners. 


\section{3) The Extrapolation}

The purpose of this third phase is to generalize the resulted marginal suitability model from the reference set of learners to all learners, by calculating the corresponding marginal suitability values for every combination of learner characteristics. This calculation is based on the interpolation of the marginal suitability values between the two closest instances of the reference set of learners.

Suppose that we have calculated the marginal suitability $S_{i}^{L_{1}}$ and $S_{i}^{L_{2}}$ of a criterion $g_{i}$ matching the characteristics of learners $L_{1}$ and $L_{2}$ respectively. We can then calculate the corresponding marginal suitability value for another learner $L$ using interpolation if the characteristics of learner $L$ are mapped inside the polyhedron that the characteristics of learners $L_{1}$ and $L_{2}$ define, using the formula:

$$
S_{i}\left(g_{i}^{L}\right)=S_{i}\left(g_{i}^{L_{1}}\right)+\frac{g_{i}^{L}-g_{i}^{L_{1}}}{g_{i}^{L_{2}}-g_{i}^{L_{1}}}\left[S_{i}\left(g_{i}^{L_{2}}\right)-S_{i}\left(g_{i}^{L_{1}}\right)\right], \text { if } S_{i}\left(g_{i}^{L_{2}}\right)>S_{i}\left(g_{i}^{L_{1}}\right)
$$

Let $C_{i}=\left\lfloor c_{i}, c_{i}^{\star}\right\rfloor, i=1,2, \ldots, n$ be the intervals in which the values of each criterion - for both learning object and learners - are found, then we call global suitability surface the space $C=\times_{i=1}^{n} C_{i}$.

The calculation of the global suitability over the above mentioned space is the addition of the marginal suitability surfaces for each of the learning object characteristics over the whole combination set of learner characteristics.

\section{Some Experimental Results and Discussion}

In order to evaluate the total efficiency of the proposed methodology both in calculating the suitability on the training set of GIS learning objects and on estimating the suitability of GIS learning objects external from the reference set, we have designed an evaluation criterion, defined by:

$$
\operatorname{Success}(\%)=100 \cdot \frac{\text { Correct Learning Objects Selected }}{n},
$$

where $n$ is the number of the desired GIS learning objects from the virtual pool that will act as input to the instructional planner.

It is assumed that the number of desired GIS learning objects is less than the total number of the GIS learning objects in the input space (the learning objects pool) and that both the GIS learning object metadata and the learner information metadata have normal distribution over the value space of each criterion.

Additionally, the GIS learning objects are classified, for both testing and estimation set, in two classes according to their functionality and aggregation level, since granularity is a parameter affecting the capability of an instructional designer to select learning content for a specific learner. The classification is based on the value space of the "General/Aggregation Leiel" element of the O-GIS . C standard.

In the rest of the paper experimental results are presented of the proposed methodology by comparing the resulting selected GIS learning objects with those selected by GIS experts. Also, the success of the proposed method has been evaluated on both the training set of learning objects (the Training Success) and on the suitability estimation of learning objects external from the reference set (the Estimation Success). So, Figure 4 present average experimental results for GIS learning objects with aggregation level 1 and 2 respectively.

If it is considered that for one learner instance, the different combinations of GIS learning objects, calculated as the multiplication of the value instances of characteristics with GIS functionality, lead to more than 1,000 GIS learning objects, it is evident that it is almost un-realistic to assume that an instructional designer can manually define the full set of selection rules which correspond to the dependencies extracted by the proposal method and at the same time to avoid the inconsistencies, confluence and insufficiency of the produced selection rules.

The proposed topology-based methodology is capable of effectively extracting dependencies between GIS learning object and learner characteristics affecting the decision of an instructional designer on the GIS learning object selection problem.

The analysis on the results, presented in Figure 3, shows that when the desired number of GIS learning objects (i.e. $n$ ) is relatively small (less than 100), the selected learning objects by the extracted decision model are almost similar to those the instructional designer would select. On the other hand, when the desired number of GIS learning objects is relatively large (say, about 500) the success of the selection is affected, but remains at acceptable level (i.e. about 90\%).

Another parameter affecting the selection success is proved to be the granularity of GIS learning objects. Granularity mainly affects the capability of an instructional designer to express selection preferences over learning 

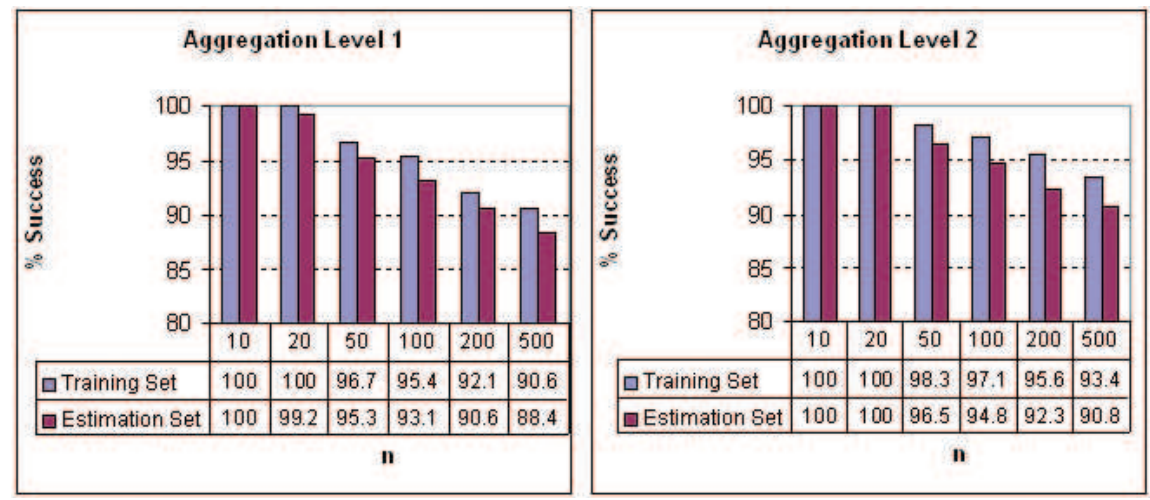

Figure 4: Average Experimental Results for GIS Learning Objects

objects. Learning objects with small aggregation level have bigger possibility of producing "gray" decision areas, where the instructional designer cannot decide which GIS learning object matches most the cognitive style or learning preferences of a learner [1,5].

In paper's experiments, GIS learning objects with aggregation level 2, which can be small or even bigger collections of GIS learning objects with aggregation level 1, appear to have less possibility of producing indifference relations, enabling to make secure decisions even for bigger desired number of learning objects $(n=1,000)$.

\section{Summary and Conclusions}

In this paper the GIS learning object selection problem is addressed as an intelligent topology-based GIS learning systems, by proposing a methodology that instead of "forcing" an instructional designer to manually define the set of selection rules; produces a decision model that mimics the way the designer decides, based on the observation of the designer's reaction over a small-scale GIS learning object selection problem.

Hence, the proposed personalized e-learning method, describes a new methodology about selecting and sequencing learning objects with GIS functionality in an instructional-sense and user-friendly way.

\section{Acknowledgements}

The current paper is supported by the EPEAEK II - ARCHIMEDES I research project (Action 2.2.17), "Personalized e-Learning in a Reusable Way", of the Alexandrium Technological Educational Institute of Thessaloniki (ATEI), Greece. This project is co-funded by the Greek Ministry of Education \& Religious Affairs and the European Union.

\section{References}

[1] L. B. Baruque \& R.N. Melo, "Learning Theory and Instructional Design using Learning Object", in Learning Objects 2003 Symposium: Lessons Learned, Questions Asked. Honolulu, Hawaii, USA. Retrieved in September 2005 from the World Wide Web: http://www.cs.kuleuven.ac.be/ erikd/PRES/2003/LO2003/Baruque.pdf

[2] P. Brusilovsky, "Adaptive and intelligent technologies for web-based education", Kunstliche Intelligenz Journal, Vol. 4, pp.19-25, 1999.

[3] P. Brusilovsky and J. Vassileva, "Course Sequencing Techniques for Large-Scale Web-based Education", International Journal of Continuing Engineering Education and Life-long Learning, Vol.13 (1/2), pp. 75-94, 2003.

[4] L. Calvi \& A. Cristea. "Towards Generic Adaptive Systems: Analysis of a Case Study", In Proc, of the 2nd International Conference on Adaptive Hypermedia and Adaptive Web Based Systems, Malaga, Spain, 2002. 
[5] K. Chitwood, et al., "Battle Stories from the Field: Wisconsin Online Resource Centre Learning Objects Project", in The Instructional Use of Learning Objects: Online Version. D.A. Wiley, ed., 2000. Retrieved in September 2005 from the World Wide Web: http://reusability.org/read/chapters/ chitwood.doc

[6] P. Dolog, W. Nejdl, "Challenges and Benefits of the Semantic Web for User Modelling”, Workshop on Adaptive Hypermedia and Adaptive Web-Based Systems, In Proc. of the 12th International World Wide Web Conference, Budapest, Hungary, 2003

[7] P. Dolog, N. Henze, W. Nejdl \& M. Sintek, "Personalization in Distributed eLearning Environments", In Proc. of the 13th International World Wide Web Conference, New York, USA, 2004

[8] EPEAEK II - Common European Union and Greek Government Project (2001-2006). World Wide Web page: http://www.epeaek.gr/epeaek/en/home.html

[9] IEEE, "Draft Standard for Learning Object Metadata", IEEE 1484.12.1-2002, 2002. Retrieved in September 2005 from the World Wide Web: http://ieeeltsc.org/wg12LOM/1484.12.1

[10] IMS - Global Learning Consortium. QTI Lite Specification. IMS Question \& Test Interoperability, 2002. Retrieved in September 2005 from the World Wide Web: http://www.imsglobal.org/question/qtilite03.html

[11] Kinshuk, R. Oppermann, A. Patel \& A. Kashihara, "Multiple Representation Approach in Multimedia based Intelligent Educational Systems", Artificial Intelligence in Education Journal, Amsterdam: IOS Press. pp. 259-266, 1999.

[12] LSAL, SCORM Best Practices Guide for Content Developers, 2003. Cernegie Mellon Learning Systems Architecture Lab. Retrieved in September 2005 from the World Wide Web: http://www.lsal.cmu.edu/lsal/expertise/projects/developersguide

[13] G. McCalla, "The Fragmentation of Culture, Learning, Teaching and Technology: Implications for the Artificial Intelligence in Education Research Agenda in 2010", International Journal of Artificial Intelligence in Education, Vol. 11, pp. 177-196, 2000.

[14] P. Mohan, J. Greer \& G. McGalla, "Instructional Planning with Learning Objects", Workshop on Knowledge Representation and Automated Reasoning for E-Learning Systems. 2003. In Proc. Of the 18th International Joint Conference on Artificial Intelligence, Acapulco, Mexico.

[15] P. R. Polsani, "Use and Abuse of Reusable Learning Objects". Journal of Digital information, (2003). Retrieved in September 2005 from the World Wide Web: http://jodi.ecs.soton.ac.uk/Articles/v03/i04/Polsani.

[16] A. Styliadis, K. Pehlivanis \& D. Zahariou, "Personalized e-Learning for GIS Lecturing". Hawaii International Conference on Education. Honolulu, Hawaii, USA, January 6th-9th, 2006.

[17] A. Styliadis, K. Pehlivanis \& D. Zahariou, "E-Learning with Re-Usable GIS Functionality". Global Universities In Distance Education (GUIDE) 2006 - Developing a Common Platform for Global Co-Operation. Rome IT, February 13th-14th, 2006.

[18] A. Styliadis \& K. Pehlivanis, "Personalized e-Learning in a Re-Usable Way: A Proposed GIS System Design - The Architecture". International Journal on Engineering and Applied Sciences (JEAS), 2005.

[19] M. S. Urban \& E. G. Barriocanal, "On the Integration of IEEE-LOM Metadata Instances and Ontologies", Learning Technology Newsletter, Vol. 5 (1), 2003.

[20] H. Wu \& P. De Bra, "Sufficient Conditions for Well-behaved Adaptive Hypermedia Systems" In Proc. of the First Asia-Pacific Conference on Web Intelligence: Research and Development, Maebashi City, Japan, 2001.

Athanasios D. Styliadis, Ioannis D. Karamitsos, Dimitrios I. Zachariou The ATEI of Thessaloniki, Greece EPEAEK II, The Arximedes 2-2-17 Project E-mail: styl@it.teithe.gr 
Editor's note about the author:

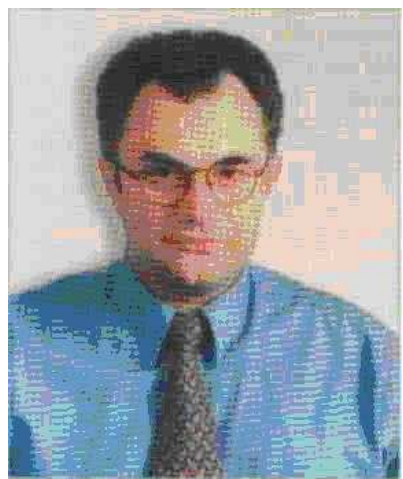

Athanasios D. Styliadis is a Professor at the Department of Information Technology at the Alexander Institute of Technology (ATEI) of Thessaloniki, Greece. He was born in 1956 in Florina, Greece and he received a Diploma in Surveying Engineering (Aristotle University of Thessaloniki, Greece, 1980), an M.Sc. in Computer Science (Dundee University, Scotland, 1987) and a Ph.D. in CAD/GIS/Computer Modeling (Aristotle University of Thessaloniki, Greece, 1997). He was a Fellow Research Scholar at the Department of Geomatics, University of Melbourne and at the Center for GIS and Modeling (CGISM), Australia. Prof. Styliadis is the writer of three books in Computer Graphics, Human-Computer Interaction (HCI) Programming and GIS-Geomatics Engineering, and he has over 70 journal and conference proceedings publications. Also, has been worked at the Hellenic Army Geographical Service (HAGS, Athens) for three years as GIS system analyst and programmer. His current research interests include: e-learning \& geographic information, computer modeling, web-based CAAD, temporal GIS systems, concurrent engineering \& 3-D geometry, and digital documentation of monuments and sites. 